\title{
PENGARUH INTERVENSI MANAJEMEN, ROTASI SEMU AUDITOR, DAN PERSEPSI FEE AUDIT TERHADAP INDEPENDENSI AUDITOR
}

\author{
I Putu Agus Atmaja Negara ${ }^{1}$ \\ Sekolah Tinggi Bisnis Putra Harapan Jembrana, Bali, Indonesia ${ }^{1}$ \\ email: agus.atmaja@triatmamulya.ac.id
}

\begin{abstract}
Financial report is an important media in communicating facts about company finances and as a basis for decision making. Many parties have an interest about the financial report of a company. Therefore a profession is needed that can guarantee that the financial report are free of fraud made by company management. This is where the auditor's role is needed. auditor independence is very important for public trust in financial reporting. This study aims to determine the effect of the influence of management intervention, pseudo auditor rotation and audit fees perception on auditor independence. The population in this study were all auditors in KAP throughout the Province of Bali. Samples were selected by purposive sampling method with the criteria that experienced auditors working at KAP at least one year, at least have done one audit assignment, and KAP is still active. The hypothesis was tested by multiple linear regression analysis. The results of this study indicate that management interventions and pseudo auditor rotation have a negative effect on auditor independence, while auditfees perception have a positive effect on auditor independence. This shows that the higher the audit fee, the auditor's independence will also increase.
\end{abstract}

Keywords: management intervention, pseudo auditor rotation, audit fees perception, auditor independence.

\section{PENDAHULUAN}

Terdapat banyak faktor yang mempengaruhi independensi auditor, salah satunya adalah intervensi manajamen. Menurut Harhitno (2004) manajemen mengintervensi auditor untuk mempengaruhi fungsi pengujian laporan keuangan dengan cara memaksa auditor melakukan tindakan yang melanggar standar audit, termasuk dalam pemberian opini yang tidak sesuai dengan keadaan klien yang sesungguhnya. Auditor sering dihadapkan pada situasi yang mengharuskan auditor untuk mengurangi kegiatan yang mengurangi kualitas audit atau biasa disebut reduced audit quality (RAQ). Tekanan dari manajemen memiliki maksud agar laporan yang diaudit oleh auditor dapat menghasilkan laporan yang baik agar pengguna laporan keuangan merasa senang. Penelitian Meilisa (2012) menunjukkan bahwa auditor yang merasa dibatasi dan dalam keadaan tertekan sedikit banyak akan terganggu bahkan cenderung mengikuti kemauan manajemen dengan memberikan opini yang tidak sesuai dengan fakta. Penelitian Prabowo dan Samsudin (2010) menyatakan bahwa intervensi manajemen klien berpengaruh positif dan signifikan terhadap independensi auditor sedangkan Hakim dan Yendrawati (2016) menyatakan bahwa 
intervensi manajemen berpengaruh negatif terhadap independensi auditor. Faktor lainnya yang mempengaruhi independensi auditor adalah rotasi KAP. Peraturan tentang rotasi wajib KAP (auditor) di Indonesia telah memaksa klien untuk melakukan rotasi KAP independen secara periodik. Namun demikian sebaliknya dalam praktik justru muncul fenomena rotasi semu, sehingga fenomena ini menjadi satu hal yang penting untuk penelitian empiris. Menurut Junaidi dkk., (2013) rotasi semu auditor (KAP) menunjukkan suatu kondisi yang secara formal berdasarkan peraturan pemerintah, telah terjadi rotasi KAP yang menyebabkan hubungan KAP dengan klien terputus, padahal secara esensial hubungan KAP dengan kliennya masih tetap berlangsung. Dalam praktiknya adanya peraturan pembatasan pemberian jasa KAP pada klien tersebut menimbulkan perilaku tricky dari KAP maupun partner untuk saling bertukar bendera maupun partner. Oleh karena itu rotasi yang terjadi seakan hanya untuk menggugurkan kewajiban karena adanya pembatasan pemberian jasa auditor (KAP) kepada klien, dan bukan karena untuk mempertahankan kualitas audit (Hakim dan Yendrawati, 2016).

Hubungan yang panjang antara auditor dan kliennya dapat merupakan ancaman terhadap independensi karena hubungan pribadi dan keakraban dapat berkembang yang dapat menyebabkan kurangnya kewaspadaan auditor (Okolie, 2014). Penelitian Hakim dan Yendrawati (2016) menyatakan rotasi semu auditor berpengaruh negatif terhadap independensi auditor namun Myers et al. (2003) menunjukkan hasil bahwa kualitas audit justru semakin meningkat seiring dengan bertambah lamanya tenur KAP dan tenur patner audit, serta penelitian Chen et al. (2008) yang membuktikan adanya peningkatan kualitas audit seiring bertambahnya tenur patner audit. Christiawan (2002) mengungkapkan bahwa kualitas audit ditentukan oleh dua hal yaitu independensi dan kompetensi. Berdasarkan definisi diatas, maka kesimpulannya adalah seorang auditor dalam menemukan pelanggaran atau salah saji harus memiliki kompetensi serta sikap kecermatan dan kehati-hatian profesional. Seorang auditor harus mempunyai kemampuan pemahaman dan keahlian teknis. Sementara itu, melaporkan pelanggaran klien merupakan sikap independensi yang harus dimiliki oleh auditor.

Selain intervensi manajeman dan rotasi semu, persepsi fee audit diketahui juga mempengaruhi independensi auditor. Fee audit merupakan pendapatan yang hasilnya bervariasi karena tergantung dari beberapa faktor dalam penugasan audit, seperti ukuran perusahaan klien, kompleksitas jasa audit yang dihadapi auditor, risiko audit yang dihadapi auditor serta nama kantor akuntan publik yang melaksanakan jasa audit (Nugrahani dan Sabeni, 2013). Auditor akan bersikap profesional dan sesuai dengan kode etik akuntansi apabila prosedur audit yang direncanakan, SDM yang berkualitas, dan program pelaksanaan audit didukung oleh berbagai faktor yang tidak luput dari dana. Kantor akuntan publik akan cenderung membuat prosedur audit yang lebih baik, SDM yang lebih berkualitas, dan prosedur audit yang lebih lama. Dengan dipertimbangkannya biaya audit, 
maka secara logika auditor akan bertindak sesuai dengan etika profesi yang berlaku, dan kinerja auditor akan semakin baik, hal inilah yang mendasari bahwa besarnya persepsi fee audit akan meningkatkan independensi auditor.

Kondisi keuangan klien yang kuat dapat memberikan fee audit yang besar dan memberikan fasilitasfasilitas audit yang baik bagi auditor. Fee yang diberikan klien tersebut bertujuan untuk memberikan semangat atau motivasi kepada auditor supaya melaksanakan tugas audit dengan sungguh-sungguh dan secara efisien (Nor, 2013). Penelitian ElGammal (2012) membuktikan bahwa perusahaan multinasional dan bankbank di Lebanon lebih memilih untuk membayar biaya audit yang bernominal besar dengan alasan yaitu mereka lebih mencari auditor dalam kantor akuntan publik yang dapat menghasilkan laporan audit yang berkualitas dan dapat meningkatkan kredibilitas laporan keuangan tahunan yang dapat bersaing diseluruh dunia. Penelitian Ika dan Wibowo (2011) serta Brilian dan Kartika (2015) menyatakan bahwa besarnya fee audit berpengaruh positif dan signifikan terhadap independensi auditor, sedangkan penelitian Retty dan Kusuma (2001) menyatakan bahwa fee audit tidak berpengaruh terhadap independensi auditor.

Penelitian ini dilakukan untuk menguji pengaruh intervensi manajemen,rotasi semu auditor serta persepsi fee audit pada independensi auditor. Alasan dipilihnya auditor-auditor kantor akuntan publik yang ada di Bali sebagai responden karena penelitianpenelitian sebelumnya mengenai pengaruh intervensi manajemen, rotasi semu auditor, persepsi fee audit pada independensi auditor difokuskan pada auditor-auditor yang ada di luar Bali, seperti Jakarta dan Yogyakarta, dan lain-lain, namun belum ada yang memfokuskan penelitiannya pada auditor-auditor KAP yang ada di Bali.

\section{TINJAUAN PUSTAKA}

\section{Pengaruh Intervensi Manajemen pada Indenpendensi Auditor}

Auditor sering dihadapkan pada situasi yang mengharuskan auditor untuk mengurangi kegiatan yang mengurangi kualitas audit atau biasa disebut reduced audit quality (RAQ). Berdasarkan dari penelitian Meilisa (2012) menunjukan bahwa auditor yang merasa dibatasi dan dalam keadaan tertekan sedikit banyak akan terganggu bahkan cenderung mengikuti kemauan manajemen dengan memberikan opini yang tidak sesuai dengan fakta. Gejala seperti ini merupakan indikasi penurunan kualitas audit dan independensi auditor. Hal ini dapat dialami oleh auditor, bahkan KAP besar sekalipun tetap rentan akan gangguan intervensi manajemen. Menurut Jatmiko dan Syamsudin (2010) independensi auditor luntur pada situasi konflik. Situasi konflik semakin meruncing ketika klien mulai melakukan intervensi pada proses audit sehingga akan mempengaruhi opini auditor atas laporan keuangan historis. Penelitian Prabowo dan Samsudin (2010) menyatakan bahwa intervensi manajemen klien berpengaruh positif dan signifikan terhadap independensi auditor sedangkan Hakim dan Yendrawati (2016) menyatakan bahwa intervensi manajemen berpengaruh negatif terhadap independensi auditor. Berdasarkan uraian tersebut, maka rumusan hipotesis $\mathrm{H}_{1}$ sebagai berikut: 
Journal of Applied Management and Accounting Science ( J A M A S )

(I Putu Agus Atmaja Negara 136 - 148)

Vol 1, No 2, Juli 2020

$\mathrm{H}_{1}$ : Intervensi manajemen

berpengaruh negatif terhadap independensi auditor.

Pengaruh Rotasi Semu Auditor pada Indenpendensi Auditor

Menurut Junaidi dkk., (2013) tenur auditor (KAP) menunjukkan lama hubungan antara auditor dengan klien. Tenur auditor panjang dapat merusak independensi auditor sebagai masa yang panjang untuk memupuk kedekatan antara manajemen dan auditor. Apabila rotasi audit tidak ada akan ada kemungkinan kasus yang terjadi pada perusahaan Enron, dimana belum adanya kebijakan rotasi audit yang menimbulkan adanya saling tukar menukar bendera hingga menyebabkan hilangnya independensi seorang auditor dan kerugian di kedua pihak. Apabila rotasi semu terus berlanjut maka dampaknya akan sama dengan tenur audit yaitu berkurangnya sikap independensi auditor. Penelitian Hakim dan Yendrawati (2016) menyatakan rotasi semu auditor berpengaruh negatif terhadap independensi auditor namun Myers et al., (2003) menunjukkan hasil bahwa kualitas audit justru semakin meningkat seiring dengan bertambah lamanya tenur KAP dan tenur partner audit, serta penelitian Chen et al., (2008) yang membuktikan adanya peningkatan kualitas audit seiring bertambahnya tenur partner audit. Christiawan (2002) mengungkapkan bahwa kualitas audit ditentukan oleh dua hal yaitu independensi dan kompetensi. Berdasarkan uraian tersebut, maka rumusan hipotesis $\mathrm{H}_{2}$ sebagai berikut:

$\mathrm{H}_{2}$ : Rotasi semu auditor berpengaruh negatif terhadap independensi auditor.
Pengaruh Persepsi Fee Audit pada
Independensi Auditor
Fee audit merupakan pendapatan yang hasilnya bervariasi karena tergantung dari beberapa faktor dalam penugasan audit, seperti ukuran perusahaan klien, kompleksitas jasa audit yang dihadapi auditor, risiko audit yang dihadapi auditor serta nama kantor akuntan publik yang melaksanakan jasa audit (Nugrahani dan Sabeni, 2013). Auditor akan bersikap profesional dan sesuai dengan kode etik akuntansi apabila prosedur audit yang direncanakan, SDM yang berkualitas, dan program pelaksanaan audit didukung oleh berbagai faktor yang tidak luput dari dana. Penelitian Ika dan Wibowo (2011) serta Brilian dan Kartika (2015) menyatakan bahwa besarnya fee audit berpengaruh positif dan signifikan terhadap independensi auditor, sedangkan penelitian Retty dan Kusuma (2001) menyatakan bahwa fee audit tidak berpengaruh terhadap independensi auditor. Hal ini dikarenakan bahwa kantor akuntan publik akan cenderung membuat prosedur audit yang lebih baik, SDM yang lebih berkualitas, dan prosedur audit yang lebih lama. Dengan dipertimbangkannya biaya audit, maka secara logika auditor akan bertindak sesuai dengan etika profesi yang berlaku, dan kinerja auditor akan semakin baik, hal inilah yang mendasari bahwa besarnya audit fee akan meningkatkan independensi auditor. Berdasarkan uraian tersebut, maka rumusan hipotesis $\mathrm{H}_{2}$ sebagai berikut:

$\mathrm{H}_{2}$ : Persepsi Fee audit berpengaruh positif terhadap independensi auditor. 


\section{METODE PENELITIAN}

Penelitian ini dilakukan di KAP Provinsi Bali. Teknik yang digunakan peneliti dalam pemilihan sampel adalah nonprobability sampling yaitu purposive sampling. Instrumen penelitian yang digunakan adalah kuesioner yang akan dijawab oleh auditor pada KAP se-Provinsi Bali. Teknik analisis yang digunakan dalam penelitian ini adalah regresi linier berganda.

\section{HASIL DAN PEMBAHASAN Hasil Uji Regresi Linier Berganda}

Pengujian hipotesis dalam penelitian ini menggunakan analisis Regresi berganda. Hasil perhitungan disajikan pada Tabel 1 .

Tabel 1.

Tabulasi Output SPSS

\begin{tabular}{lccc}
\hline \multicolumn{1}{c}{ Variabel } & $\begin{array}{c}\text { Standardized } \\
\text { Beta }\end{array}$ & $\begin{array}{c}\text { Probabilitas } \\
\text { (sig.) }\end{array}$ & Keterangan \\
\hline Konstanta & 13,466 & 0,000 & Signifikan \\
Intervensi Manajemen (IM) & $-0,317$ & 0,008 & Signifikan \\
Rotasi Semu Auditor (RA) & $-0,412$ & 0,001 & Signifikan \\
Persepsi Fee Audit (FA) & 0,251 & 0,037 & \\
Adjusted R Square & & 0,577 & \\
F Statistik & & 21,485 & \\
Probabilitas (p-value) & & 0,000 & \\
Variabel Dependen & & Independensi Auditor (IA) \\
\hline
\end{tabular}

Data Primer, 2020

Berdasarkan persamaan regresi linier berganda untuk variabel dependen Independensi Auditor yang telah diperoleh, terdapat nilai konstanta sebesar 13,466 yang artinya jika variabel independensi auditor tidak dipengaruhi oleh semua variabel independen, maka besarnya rata-rata independensi auditor adalah 13,466.

Nilai-nilai koefisien regresi pada variabel-variabel bebasnya menunjukan jika variabel bebasnya dinaikkan nilai sebesar satu unit dan variabel bebas lainnya konstanta atau nilai lainnya sama dengan nol, maka nilai variabel dependen akan disesuaikan dengan koefisien regresinya

Koefisien regresi untuk variabel independen Intervensi Manajemen (X1) bernilai negatif, menunjukkan adanya hubungan tidak searah antara Intervensi Manajemen dengan Independensi Auditor (Y).
Koefisien regresi variabel Intervensi Manajemen sebesar $-0,317$ mengandung arti untuk setiap kenaikan satu basis poin Intervensi Manajemen akan menyebabkan penurunan Independensi Auditor sebesar 0,317 basis poin.

Koefisien regresi untuk variabel independen Rotasi Semu Auditor (X2) bernilai negatif, menunjukkan adanya hubungan yang tidak searah antara Rotasi Semu Auditor dengan Independensi Auditor (Y). Koefisien regresi variabel Rotasi Semu Auditor sebesar -0,412 mengandung arti untuk setiap kenaikan satu basis poin Rotasi Semu Auditor akan menyebabkan penurunan Independensi Auditor sebesar 0,412 basis poin.

Koefisien regresi untuk variabel independent Persepsi Fee Audit (X3) bernilai positif, menunjukkan adanya hubungan yang 
searah antara Persepsi Fee Audit dengan Independensi Auditor (Y). Koefisien regresi variabel Persepsi Fee Audit sebesar 0,251 mengandung arti untuk setiap kenaikan satu basis poin Persepsi Fee Audit akan menyebabkan meningkatnya Independensi Auditor sebesar 0,251 basis poin.

\section{Koefisien Determinasi (Adjusted R Square)}

Berdasarkan Tabel 1 nilai adjusted $\mathrm{R}$ square sebesar 0,577 menunjukkan bahwa $57,7 \%$ variasi nilai Independensi Auditor dapat dijelaskan oleh faktor-faktor Intervensi Manajemen, Rotasi Semu Auditor, dan Persepsi Fee Audit. Sedangkan sisanya sebesar $42,3 \%$ dipengaruhi oleh faktor lain yang tidak diamati dalam penelitian ini.

\section{Uji Kelayakan Model Nilai F}

Hasil pengujian p-value menunjukkan nilai 0,000 lebih kecil dari 0,05 berarti Intervensi Manajemen, Rotasi Semu Auditor, dan Persepsi Fee Audit secara bersama-sama berpengaruh signifikan pada Independensi Auditor.

\section{Uji Signifikasi Nilai $\mathbf{t}$}

Berdasarkan Tabel 1 dapat dijelaskan analisis secara parsial setiap variabel. Variabel intervensi manajemen memiliki koefisien negatif sebesar -0,317 dengan nilai signifikasi sebesar $0,008<0,05$ berarti Intervensi Manajemen mempunyai pengaruh negatif pada Independensi Auditor. Hipotesis 1 dalam penelitian diterima.Variabel Rotasi Semu Auditor memiliki koefisien negative sebesar -0,412 dengan nilai signifikan sebesar $0,001<0,05$ berarti Rotasi Semu Auditor mempunyai pengaruh negatif pada Independensi Auditor.
Hipotesis 2 dalam penelitian diterima. Variabel Persepsi Fee Audit memiliki koefisien positif sebesar 0,251 dengan nilai signifikasi sebesar $0,037<0,05$ berarti Persepsi Fee Audit mempunyai pengaruh positif pada Independensi Auditor. Hipotesis 3 dalam penelitian diterima.

\section{Pengaruh Intervensi Manajemen pada Independensi Auditor}

Berdasarkan hasil pengujian hipotesis pada pembahasan sebelumnya menyatakan hipotesis 1 diterima. Hasil ini menunjukkan bahwa intervensi manajemen memiliki pengaruh negatif signifikan terhadap independensi auditor. Semakin kuat intervensi manajemen menyebabkan independensi auditor semakin lemah. Hasil ini juga diperkuat oleh beberapa hasil penelitian sebagai berikut: Penelitian Meilisa (2012) menunjukan bahwa auditor yang merasa dibatasi dan dalam keadaan tertekan sedikit banyak akan terganggu bahkan cenderung mengikuti kemauan manajemen dengan memberikan opini yang tidak sesuai dengan fakta. Gejala seperti ini merupakan indikasi penurunan kualitas audit dan independensi auditor. Menurut Jatmiko dan Syamsudin (2010) independensi auditor luntur pada situasi konflik. Situasi konflik semakin meruncing ketika klien mulai melakukan intervensi pada proses audit sehingga akan mempengaruhi opini auditor atas laporan keuangan historis. Penelitian Hakim dan Yendrawati (2016) menyatakan bahwa intervensi manajemen berpengaruh negatif terhadap independensi auditor. Wiwekandari (2015) menyatakan bahwa tekanan anggaran waktu dan intervensi manajemen klien berpengaruh negatif secara parsial 
terhadap independensi auditor dan kualitas audit. Hal ini berarti semakin tinggi tekanan anggaran waktu dan intervensi manajemen klien yang dialami oleh auditor maka independensi auditor dan kualitas audit yang dihasilkan semakin rendah. Hakim dan Yendrawati (2016) menyatakan bahwa intervensi manajemen berpengaruh negatif dan signifikan terhadap independensi auditor. Meilisa (2016) menyatakan bahwa intervensi manajemen berpengaruh negatif dan signifikan terhadap independensi auditor. Kurnia, Yuli Endah (2018) menyatakan bahwa menyatakan bahwa intervensi manajemen berpengaruh negatif dan signifikan terhadap independensi auditor. Prabowo dan Samsudin (2010) menyatakan bahwa tekanan manajemen berpengaruh negatif dan signifikan terhadap independensi auditor. Nicholas dan Price (1976) juga menyatakan bahwa independensi auditor tekanan manajemen dipengaruhi oleh tekanan manajemen.

\section{Pengaruh Rotasi Semu Auditor pada Independensi Auditor}

Berdasarkan hasil pengujian hipotesis pada pembahasan sebelumnya menyatakan hipotesis 2 diterima. Hasil ini menunjukkan bahwa rotasi semu auditor memiliki pengaruh negatif signifikan terhadap independensi auditor. Semakin banyak melakukan rotasi semu menyebabkan independensi auditor semakin lemah. Rotasi semu auditor menjadi salah satu alasan seorang auditor untuk tetap mempertahankan kliennya selama waktu yang telah disepakati. Rotasi semu didalam penelitian ini memberikan pengaruh negatif terhadap independensi auditor dan dapat diartikan bahawa apabila rotasi semu yang auditor yang dilakukan sudah lama hingga melebihi waktu bertahun tahun itu dapat menurunkan independensi auditor. Menurunnya independensi seorang auditor diakibatkan karena hubungan yang terjalin antara klien dengan auditor sudah sangat lama sehingga auditor yang diminta untuk mengaudit perusahaan klien tersebut pun hanya menjalankan tugasnya tanpa memperhatikan etika-etika yang dimiliki oleh seorang auditor.

Hasil dari penelitian ini sesuai dengan penelitian yang telah dilakukan oleh Junaidi et al., (2013) serta Hakim dan Yendrawati (2016) yang membuktikan bahwa rotasi semu auditor berpengaruh negatif terhadap independensi auditor. Hubungan yang panjang antara auditor dan kliennya dapat merupakan ancaman terhadap independensi karena hubungan pribadi dan keakraban dapat berkembang yang dapat menyebabkan kurangnya kewaspadaan auditor (Okolie, 2014).

\section{Pengaruh Persepsi Fee Audit pada Independensi Auditor}

Berdasarkan hasil pengujian hipotesis pada pembahasan sebelumnya menyatakan hipotesis 3 diterima. Hasil ini menunjukkan bahwa semakin tinggi persepsi fee audit maka kecenderungan independensi auditor juga semakin tinggi. Fee audit merupakan pendapatan yang hasilnya bervariasi karena tergantung dari beberapa faktor dalam penugasan audit, seperti ukuran perusahaan klien, kompleksitas jasa audit yang dihadapi auditor, risiko audit yang dihadapi auditor serta nama kantor akuntan publik yang melaksanakan jasa audit (Nugrahani dan Sabeni, 2013). Auditor akan 
bersikap profesional dan sesuai dengan kode etik akuntansi apabila prosedur audit yang direncanakan, SDM yang berkualitas, dan program pelaksanaan audit didukung oleh berbagai faktor yang tidak luput dari dana. Penelitian Brilian dan Kartika (2015), Cahyadi (2013), John et. al., (2013), Dahlan dkk (2012), Putri dkk (2012), Maryati (2012), Ika dan Wibowo (2011), dan Abu Bakar et. al., (2009), menyatakan bahwa besarnya fee audit berpengaruh positif dan signifikan terhadap independensi auditor. Hal ini dikarenakan bahwa kantor akuntan publik akan cenderung membuat prosedur audit yang lebih baik, SDM yang lebih berkualitas, dan prosedur audit yang lebih lama. Dengan dipertimbangkannya biaya audit, maka secara logika auditor akan bertindak sesuai dengan etika profesi yang berlaku, dan kinerja auditor akan semakin baik, hal inilah yang mendasari bahwa besarnya persepsi fee audit akan meningkatkan independensi auditor.

\section{SIMPULAN DAN SARAN Simpulan}

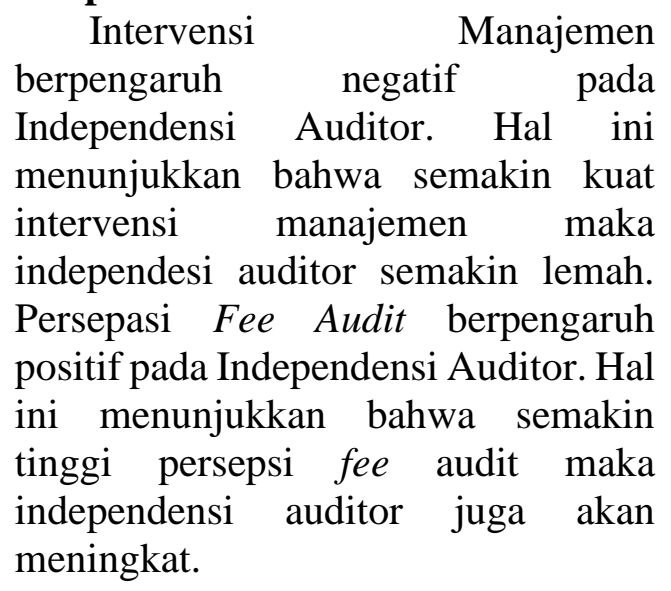
Saran

Penelitian selanjutnya sebaiknya melakukan sosialisasi atau penjelasan kepada responden mengenai maksud dan tujuan penelitian sehingga dapat menimbulkan persepsi yang sama antara peneliti dengan responden. Penelitian selanjutnya sebaiknya menambahkan variabel baru selain variabel intervensi manajemen, rotasi semu, dan persepsi fee audit. Memperluas area penyebaran kuesioner tidak hanya di Bali dan memperbanyak jumlah responden agar data yang didapatkan lebih merata dan lebih baik dari penelitian sebelumnya.

\section{DAFTAR PUSTAKA}

Abu-Bakar, N.B., and Ahmad, M. (2009), Auditor Independence: Malaysian Accountants' Per ceptions, International Journal of Bussines and Management, Vol. 4, No. 12.

Aditama, Ananta dan Utama, Karya. 2015. Pengaruh Audit Fee, Non Audit Services, dan Audit Tenure pada Independensi Auditor. Jurnal Akuntansi Universitas Udayana. Vol.13, No.3, hal: 1164-1189.

Allen, William T and Siegel, Arthur. 2002. Threats and Safeguards in the Determination of Auditor Independence. Washington University Law Review.Volume 80.

Ashari, Aizhar dan Prabowo, Tri Jatmoko Wahyu. 2017. Pengaruh Tekanan dan Lama Penugasan Terhadap Independensi Auditor Eksternal Pemerintah. Jurnal Akuntansi Universitas Diponegoro. Vol.6, No.1, hal: 1-14. 
Bazerman, Max H., Kimberly P. Morgan, dan george F Loewenstein. 1997. Opinion: The Impossibility of Auditor Independence. Sloan Manangement Review. Vol 38, No.4.

Brilian, Akbar Rakai A.W.S, dan Kartika, Andi. 2015. FaktorFaktor yang Mempengaruhi Independensi Auditor di Jawa Tengah. Dinamika Akuntansi, Keuangan dan Perbankan. Vol.4, No.2, Hal:124-135.

Burhanudin, Muhammad Alifzuda. 2016. Pengaruh Akuntabilitas dan Independensi Auditor Terhadap Kualitas Audit pada Kantor Akuntan Publik di Yogyakarta. Jurnal Akuntansi Universitas Negeri

Yogyakarta. Hal: 66-70.

Cahyadi, Hadi. (2013). Faktor-Faktor yang Mem pengaruhi Independensi Akuntan Publik: Studi pada Mahasiswa Jurusan Akuntansi Universitas di Jakarta. Jurnal Akuntansi dan Auditing Indonesia, Vol.1 No.2, 36-36.

Christiawan, Yulius Jogi. 2002. Kompetensi dan Independensi Akuntan Publik: Refleksi Hasil Penelitian Empiris. Jurnal Akuntansi \& Keuangan, Vol. 4, No. 2, hal 79-92.

Dahlan, Ahmad, Pagalung dan Tawakal. (2012). Factors Affecting Auditor Independence. Jurnal Akuntansi dan Auditing. Makassar. Fakultas Ilmu
Ekonomi Universitas Fajar Makassar.

DeAngelo, L. E. (1981). Auditor size and audit quality, Journal of Accounting and Economics, 3 (3), $183-199$.

El-Gammal, W. (2012). Determinants of Audit Fees: Evidence From Lebanon. International Business Research, 5(11), 136.

Ghozali, Imam. 2009. Aplikasi Analisis Multivariative dengan Program SPSS. Semarang: Badan Penerbit Universitas Diponegoro.

Hakim, Achmad Al., dan Yendrawati, Reni. 2016. Analisis Pengaruh Intervensi Manajemen dan Rotasi Semu Auditor terhadap Independensi Auditor dengan Fee audit sebagai variabel Moderasi. Simposium Nasional Akuntansi XIX, Lampung.

Halim, Abdul. 2008. Auditing (DasarDasar Audit Laporan Keuangan). Edisi Keempat. Jilid 1. Yogyakarta: Sekolah Tinggi Ilmu Manajemen YKPN.

Harhinto, Teguh. 2004. "Pengaruh Keahlian dan Independensi Terhadap Kualitas Audit Studi Empiris pada KAP di Jawa Timur" (tesis). Semarang: Universitas Diponegoro.

Hartadi, Bambang. 2012. Pengaruh Fee Audit, Rotasi KAP, dan Reputasi Auditor Terhadap Kualitas Audit di Bursa Efek 
Indonesia. Jurnal Ekonomi dan Keuangan. Vol.16, No.1, hal: 84-103.

Ika, Aridani dan Wibowo, Ricky Satria. 2011. Analisis FaktorFaktor yang Mempengaruhi Independensi Penampilan Akuntan Publik. Jurnal Dinamika Akuntansi. Vol.3, No.2, hal: 90-100.

Islahuzzaman. 2012. Istilah-istilah Akuntansi \& Auditing. Edisi Kesatu. Jakarta: Bumi Aksara.

Jensen, M.C and Meckling, W.H. 1976. Theory of the Firm: Managerial Behavior, Agency Cost and Ownership Structure. Journal of financial Economics.Hal:305-360.

Jogianto. 2007. Metode Penelitian Bisnis: Salah Kaprah dan Pengalaman-Pengalaman. Yogyakarta: BPFE.

John, Akinyomi .O and Tasie, C. (2012) Percep tions of Accountants on Factors Affecting Auditor's Independence in Nigeria. Nigeria. Harmony Steel Construction Company Ltd. Vol. 2, No.2

Kamus Besar Bahasa Indonesia. 2006. Jakarta: Balai Pustaka.

Kasidi. (2007). Faktor-Faktor yang Mempengaruhi Independensi Auditor. Tesis. Universitas Diponegoro. Semarang.

Kurnia, Yuli Endah. 2018. Pengaruh tenure of audit dan nintervensi manajemen terhadap independensia uditor dengan High fee audit sebagai variabel pemoderasi (studi empiris pada KAP di Yogyakarta). Skripsi. Sekolah tinggi ilmu ekonomi widya wiwaha: Yogyakarta.

MacLullich, K. \& Sucher, P. (2005). A local realisation of auditor independence construct in Poland: Counteracting 'iron curtain' syndrome in academic writing. Critical Perspectives on Accounting. Vol.16, No.5

Malik, Abdul.2017. Ernst \& Young Indonesia Didenda di AS, Ini Tanggapan Indosat. Tempo.Co., 11 Februari 2017., (Cited:16 Agustus 2018). Available from: URL: https://bisnis.tempo.co/read/84 5617/ernst-young-indonesiadidenda-di-as-ini-tanggapanindosat/full\&view $=\mathrm{ok}$

Maryati, Siti. 2012. Faktor-Faktor yang Mempengaruhi Independensi Auditor (Studi Empiris Pada Kantor Akuntan Publik di Jakarta). Skripsi. Fakultas Ekonomi Universitas Budi Luhur.

Mautz, R.K dan Sharaf, H.A. 1993. The Philosophy of Auditing. Sarasota: American Accounting Association.

Meilisa, heni. 2012. Pengaruh management pressure dan audit time budget pressure terhadap independensi auditor (studi empiris pada kantor akuntan publik di sumatera 
bagian selatan. Skripsi. Universitas lampung.

Menteri Keuangan. 2008. Peraturan Menteri Keuangan nomor: 17/pmk.01/2008, Tentang Jasa Akuntan Publik.

Mulyadi. 2006. Auditing. Edisi Ketujuh. Jakarta: Salemba Empat.

Mulyadi. 2010. Auditing. Edisi Ketujuh. Jakarta: Salemba Empat.

Nicholas dan Price. 1976. The Auditor-Firm Conflict: An Analysis Using Concepts of Exchange Theory

Nugrahani, Nadia Rizki dan Sabeni, Arifin. 2013. Faktor-faktor yang Mempengaruhi Penetapan Fee Audit Eksternal pada Perusahaan yang Terdaftar di BEI. Diponegoro Journal of Accounting. Volume 2, Nomor2.

Ojo, Marianne. 2006. Audit Independence: Its Importance to the External Auditor's Role in Banking Regulation and Supervision. MPRA Paper. No.231

Okolie, A. O. 2014. Accrual - Based earnings Management, Corporate Policies and Managerial Decisions of Quoted Companies in Nigeria, Research Journal of Finance and Accounting. Vol.5, No.2.

Okolie, Augustine O. 2014. Auditor Tenure, Auditor Independence
And Accrual- Based Earnings Management Of Quited Companies in Nigeria. European Journal of Accounting Auditing and Finance Research. Vol.2, No.2.

Ottaway, J (2014). Improving auditor independence in Australia: Is mandatory audit firm rotation the best option? Available at: http://law.unimelb.edu.au/_d ata/assets/pdf_file/0004/17095 09/27-OTTAWAYJoanneMandatoryAuditFirmRotation Paper2.pdf (accessed 7 Desember 2017).

Pemerintah Republik Indonesia. 2015. Peraturan Pemerintah Republik Indonesia Nomor 20 Tahun 2015 tentang Praktik Akuntan Publik. Jakarta: Sekretariat Negara.

Prabowo,Tri Jatmiko Wahyu dan Samsudi, Deni. 2010. Pengaruh Tekanan Manajemen Klien dan Audit Time Budget Pressure Terhadap Independensi Auditor. Jurnal Magister Akuntansi. Vol.10,No.1, hal:74-88.

Prawirosentono, Suyadi. 1999. Kebijakan Kinerja Karyawan. Yogyakarta: BPFE

Putri, Kirana dan Hardi. (2012). Faktor-Faktor yang Mempengaruhi Independensi Akuntan Publik dalam Pelaksanaan Audit: Studi Survey pada KAP di Batam dan Pekanbaru. Jurnal Ekonomi dan Bisnis Indonesia. 
Retty, Novianty dan Kusuma, Indra Wijaya. 2001. Analisis FaktorFaktor yang Mempengaruhi Independensi Penampilan Akuntan Publik. Jurnal Akuntansi dan Auditing Indonesia. Vol.5, No.1, hal: 113 .

Robbins, S.P dan Timothy A. Judge. 2015. Perilaku Organisasi. Edisi 16. Jakarta: Salemba Empat.

Soraya, Ella., dan Haridhi, Mustafa. 2017. Faktor-Faktor yang mempengaruhi auditor switching (studi Empiris pada perusahaan non financing yang terdaftar di bursa efek indonesia tahun 2011-2015). Jurnal Ilmiah Mahasiswa Ekonomi Akuntansi (JIMEKA). Vol. 2, No. 1, (2017) Halaman 48-62

Sugiyono, Agus. 2007. Statistika Untuk Penelitian. Cetakan keduabelas. Bandung: Alfabeta.

Sugiyono, Agus. 2009. Metode Penelitian Bisnis. Bandung: CV. ALFABET.

Sugiyono, Agus. 2010. Metode Penelitian Bisnis (Pendekatan Kuantitatif, Kualitatif dan $R \& D)$. Bandung: Alfabeta.

Sugiyono, Agus. 2013. Metode Penelitian Kuantitatif, Kualitatif, dan Kombinasi. Bandung: CV. ALFABETA.

Sulistiarini, Endina, dan Sudarno. 2012. "Analisis Faktor-Faktor Pergantian Kantor Akuntan
Publik (Studi Empiris Pada Perusahaan Manufaktur di Bursa Efek Indonesia Periode 2006-2010)". Diponegoro Journal Of Accounting, vol. 1 No.2.

Sukrisno, Agoes. (2012). Auditing Petunjuk Praktis Pemeriksaan Akuntan Oleh Akuntan Publik. Jakarta: Salemba Empat.

Sumarsono. 2004. Metode Riset Sumber Daya Manusia. Yogyakarta: Graha Ilmu.

Supriyono, R.A. 1988. "Pemeriksaan akuntan: Faktor-faktor yang mempengaruhi Independensi Penampilan Akuntan Publik, Suatu Hasil Penelitian Empiris di Indonesia" (tesis). Yogyakarta: Program Pasca sarjana Magister Sains Akuntansi UGM.

Velte, Patrick dan Eulerich, Marc. 2014. Increased Auditor Independence By external Rotation and Separating Audit and Non Audit duties?-A Note on The Europrann Audit Regulation. Journal of Governance and Regulation.Vol.3.

Wiwekandari, Ni Made. 2015. Pegaruh Tekanan Anggaran Waktu dan Intervensi Manajemen Klien Terhadap Independensi Auditor Serta Impilkasinya pada Kualitas Audit. Jurnal Ekonomi dan Bisnis.

$\mathrm{Wu}$, Huiying dan Ying, Sammy Xiaoyan. 2016. Realizing 
Journal of Applied Management and Accounting Science ( J A M A S )

(I Putu Agus Atmaja Negara 136 - 148)

Vol 1, No 2, Juli 2020

Auditor Independence in

China: Insights from the Local

Context. Contemporary

Management Research. Vol.

12, No. 2. 